\title{
Tetrastarch in cardiac surgery: error, confounding and bias in a meta-analysis of randomized trials
}

\author{
Roberta J Navickis ${ }^{1}$, Gary R Haynes ${ }^{2}$ and Mahlon M Wilkes ${ }^{1 *}$ \\ See related research by Jacob et al., http://ccforum.com/content/18/6/656
}

In a meta-analysis of cardiac surgery trials, we showed that hydroxyethyl starch increases postoperative blood loss, blood product transfusion and reoperation for bleeding [1]. Citing that meta-analysis, the US Food and Drug Administration determined excess bleeding to be a class effect of hydroxyethyl starch solutions and issued a safety warning [2].

Jacob and colleagues report a new meta-analysis suggesting lower perioperative blood loss with tetrastarch than albumin across three trials [3]. However, postoperative blood loss was in the opposite direction (Figure 1). By imputing key unreported data instead of contacting the trial investigators, Jacob and colleagues introduced major errors favoring tetrastarch; for example, inflating the blood loss difference in one trial by 2.3 -fold. Furthermore, the other two trials were confounded by exposure of one group to both test fluids. The potential distortion is highlighted by a randomized trial in which coadministration of low-dose albumin with tetrastarch reduced blood loss by $21 \%$ $(P<0.05)$ versus tetrastarch alone [4]. Without confounding the blood loss differences would almost certainly have been larger, and any meta-analysis incorporating the confounded trials is likely to be biased in favor of tetrastarch.

Their finding of lower blood loss with tetrastarch than pentastarch is attributable to publication bias, since an unpublished trial with higher blood loss and more frequent reoperation for bleeding after tetrastarch was omitted $[1,5]$. The omitted trial had been submitted to the US Food and Drug Administration in a New Drug Application by the same tetrastarch manufacturer who commissioned the new meta-analysis. That trial was included in two previous meta-analyses [1,5].

\section{Competing interests}

RJN and MMW have received previous unrestricted research grant support from Baxter, CSL Behring and Grifols. GRH has served as a consultant to Covidien Inc.

\section{Authors' contributions}

All authors participated in the conceptualization and composition of the letter All authors revised the letter and read and approved the final manuscript.

\section{Acknowledgements}

The authors gratefully acknowledge the cooperation of Anne Kuitunen, Young Lan Kwak, Tomi Niemi and Alexey Schramko in furnishing blood loss data from their trials.

This work is solely that of the authors. No other individual or organization contributed substantially to the conception of the letter or to manuscript preparation and revision.

\section{Author details}

${ }^{1}$ Hygeia Associates, 17988 Brewer Road, Grass Valley, CA 95949, USA. ${ }^{2}$ Department of Anesthesia Services, Cabell Huntington Hospital, $1340 \mathrm{Hal}$ Greer Boulevard, Huntington, WV 25701, USA.

Published online: 22 April 2015

\section{References}

1. Navickis RJ, Haynes GR, Wilkes MM. Effect of hydroxyethyl starch on bleeding after cardiopulmonary bypass: a meta-analysis of randomized trials. J Thorac Cardiovasc Surg. 2012;144:223-30.

2. Food and Drug Administration. FDA Safety Communication: boxed warning on increased mortality and severe renal injury, and additional warning on risk of bleeding, for use of hydroxyethyl starch solutions in some settings (2013). www.fda.gov/BiologicsBloodVaccines/SafetyAvailability/ucm358271. htm. Accessed 5 Feb 2015.

3. Jacob M, Fellahi IL, Chappell D, Kurz A. The impact of hydroxyethyl starches in cardiac surgery: a meta-analysis. Crit Care. 2014;18:656.

4. Kamra C, Beney A. Human albumin in extracorporeal prime: effect on platelet function and bleeding. Perfusion. 2013;28:536-40.

5. Kozek-Langenecker SA, Jungheinrich C, Sauermann W, van der Linden P. The effects of hydroxyethyl starch 130/0.4 (6\%) on blood loss and use of blood products in major surgery: a pooled analysis of randomized clinical trials. Anesth Analg. 2008;107:382-90.

6. Niemi T, Schramko A, Kuitunen A, Kukkonen S, Suojaranta-Ylinen R. Haemodynamics and acid-base equilibrium after cardiac surgery: comparison of rapidly degradable hydroxyethyl starch solutions and albumin. Scand J Surg. 2008;97:259-65.

7. Choi YS, Shim JK, Hong SW, Kim JC, Kwak YL. Comparing the effects of $5 \%$ albumin and 6\% hydroxyethyl starch 130/0.4 on coagulation and inflammatory response when used as priming solutions for cardiopulmonary bypass. Minerva Anestesiol. 2010;76:584-91.

8. Hanart C, Khalife M, De Villé A, Otte F, De Hert S, van der Linden P. Perioperative volume replacement in children undergoing cardiac surgery: albumin versus hydroxyethyl starch 130/0.4. Crit Care Med. 2009;37:696-701.

\footnotetext{
* Correspondence: mwilkes@hygeiaassociates.com

'Hygeia Associates, 17988 Brewer Road, Grass Valley, CA 95949, USA

Full list of author information is available at the end of the article
}

\section{Ciomed Central}

(c) 2015 Navickis et al; licensee BioMed Central. This is an Open Access article distributed under the terms of the Creative Commons Attribution License (http://creativecommons.org/licenses/by/4.0), which permits unrestricted use, distribution, and reproduction in any medium, provided the original work is properly credited. The Creative Commons Public Domain Dedication waiver (http://creativecommons.org/publicdomain/zero/1.0/) applies to the data made available in this article, unless otherwise stated. 


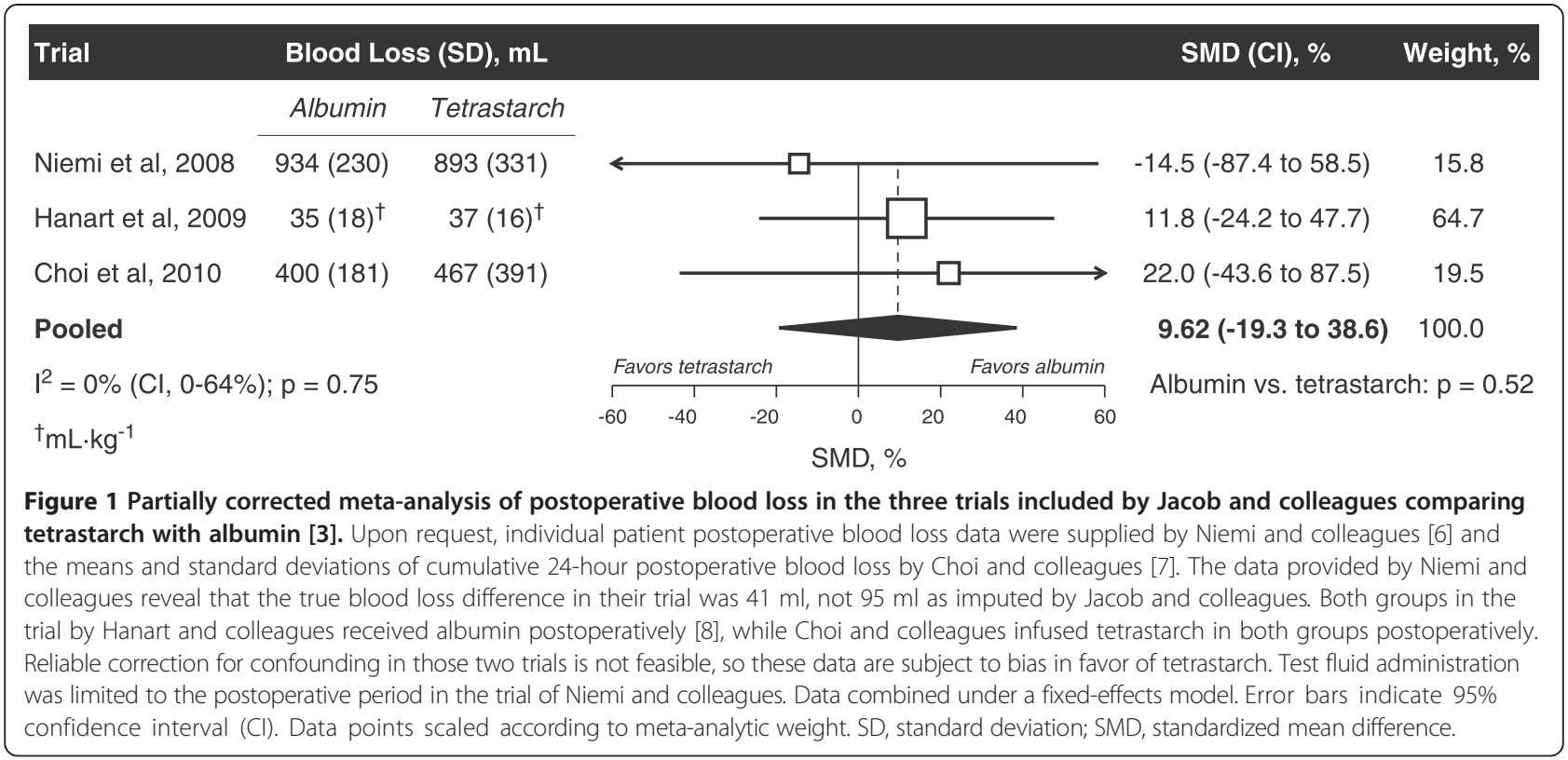

